\title{
MULTIMEDIA BERFITUR PUZZLE UNTUK MATERI PERJUANGAN MEMPROKLAMASIKAN KEMERDEKAAN INDONESIA
}

Febri Prasetiawan, Zainul Abidin, Eka Pramono Adi

Teknologi Pendidikan Fakultas Ilmu Pendidikan Universitas Negeri Malang

Jalan Semarang No. 5 Malang Jawa Timur Indonesia

Email: febri.prasetiawan9@gmail.com

\begin{tabular}{|l|l}
\hline Article History & Abstrak \\
\hline Received:April 29, 2019 & $\begin{array}{l}\text { Tujuan pengembangan adalah untuk menghasilkan multimedia berfitur } \\
\text { puzzle kemerdekaan Indonesia yang valid dan efektif. Metode } \\
\text { Accepted: June 10,2019 } \\
\text { Published:June 22,2019 } \\
\text { dengan Lee dan Owens, mengganti tahap penulisan naskah media dan } \\
\text { produksi dengan desain dan pengembangan. Berdasarkan hasil validasi dari } \\
\text { ahli media dan ahli materi diperoleh tingkat validitas sebesar 97,85\% dan }\end{array}$ \\
\hline Keywords & $\begin{array}{l}\text { 89,81\%, berdasarkan hasil uji coba dari perorangan, kelompok kecil, dan } \\
\text { lapangan diperoleh hasil 95,19\%, 92,41\%, dan 86,31\%.Pada hasil belajar } \\
\text { dibagi uji coba perorangan (2 siswa memenuhi KKM), uji coba kelompok } \\
\text { kecil (6 dari 7 siswa memenuhi KKM), dan uji coba lapangan (18 dari 22 } \\
\text { siswa memenuhi KKM), mendapatkan hasil bahwa multimedia kemerdekaan }\end{array}$ \\
\hline $\begin{array}{l}\text { Indonesia dinyatakan valid dan efektif dalam pemanfaatan pembelajaran, } \\
\text { pengembangan } \\
\text { multimedia; puzzle; } \\
\text { kemerdekaan Indonesia pada siswa lebih aktif, sangat antusias dalam pemanfatan, } \\
\text { memahami materi, dan hasil tes terlihat banyak siswa yang telah lulus KKM } \\
\text { setelah memanfatkan multimedia. }\end{array}$ \\
\hline
\end{tabular}

\section{PENDAHULUAN}

Teknologi informasi dan komunikasi (TIK) berkembang dengan pesat, sangat membantu dalam semua bidang seperti pembuatan arsitektur bangunan yang menggunakan aplikasi 3 dimensi, untuk bidang permainan (game) sekarang memasuki era virtual reality walaupun masih perkembangan awal. Penerapan media dan teknologi membantu guru dan siswa untuk pembelajaran lebih mudah dan pengalaman belajar bermanfaat (Praherdhiono, 2017). Media pembelajaran yang menerapkan perkembangan teknologi yaitu media game. Game merupakan sebuah bentuk hiburan multimedia dibuat menarik yang menjadi penghilang rasa penat dari rutinitas dan aktivitas sehingga mendapatkan kepuasan batin (Asrofi, 2016). Game mempunyai sisi baik ialah game yang membantu pengguna untuk melatih otak. Contoh game monopoli online yang penggunanya harus menyusun strategi untuk menguasai arena dan mengalahkan lawan, dan game puzzle pada permainannya pengguna diharuskan menyusun perbagian atau perpotongan 
untuk menyusun sebuah gambar. Penyaluran pengetahuan dari game komputer dengan cara merancang game yang berisi konten pembelajaran dan disesuaikan dengan tujuan pembelajaran (Tobias, 2014).

Pemakaian game dalam proses pembelajaran dapat memudahkan pemahaman siswa, sehingga pemahaman materi pelajaran dapat dilakukan dengan mudah. Aktivitas siswa dalam bermain dan belajar menjadi aktivitas yang membantu dalam tercapainya perkembangan anak yang utuh dari segi emosional, fisik, intelektual, moral, dan sosial (Munandar, 2012). Pemakaian game untuk pembelajaran membantu untuk terlibat aktif dengan materi pelajaran, tetapi untuk penerapan game dalam kegiatan belajar sangat susah dan sedikit diterapkan di kelas. Bermain dapat memberikan anak kesempatan untuk berfikir dan bertindak imajinatif dengan penuh daya khayal, berhubungan dengan berkembangnya kreativitas anak (Rusman, 2009). "Gamifikasi adalah mekanisme berbasis permainan, estetika, berfikir untuk mengajak masyarakat, memotivasi, meningkatkan minat belajar, dan memecahkan masalah" (Kapp, 2012:10). Menurut Reiners \& Wood (2015: 317) " Gamifikasi adalah penggunaan permainan pemikiran dan mekanik di dalam konteks non-game untuk melibatkan pengguna dan memecahkan masalah". Maka dapat disimpulkan Gamifikasi adalah mekanisme berbasis permainan, estetika, dan berfikir di dalam konteks non-game untuk memotivasi, meningkatkan minat belajar dan memecahkan masalah. Dari teori tersebut penggunaan game dalam pembelajaran dapat menjadi acuan dalam pembuatan game pembelajaran yang memiliki unsur non-game.

Pembelajaran berbasis game dapat menjadi solusi atau alternatif untuk meningkatkan motivasi belajar siswa (Sukirman, 2017). Penggunaan teknologi dalam pendidikan sangat membantu dalam pembelajaran, apalagi ketika pembelajaran pada pendidikan formal di kelas masih menggunakan pembelajaran interaksi guru dan siswa. Teknologi multimedia secara keseluruhan semakin menarik, semakin mudah dan sama sekali bukan hal yang menakutkan untuk dipelajari. Sejak pengolah data video bergeser dari arah analog ke digital, kemudahan-kemudahan semakin bertambah, utamanya dalam hal mencapai hasil dengan kualitas tinggi dengan hanya mempergunakan bantuan teknik know how yang minimal (Purnama, 2013). Peranan multimedia juga digunakan sebagai komunikasi sehingga proses pembelajaran dapat secara efektif dilakukan. Multimedia ini juga memiliki manfaat mencapai tujuan pembelajaran secara mudah dengan berbagai inovasi yang diberikan dalam pemanfaatan multimedia (Rusman, 2009:80).

Media gambar mempunyai kelemahan pada saat digunakan maka peneliti menggunakan pilihan permainan pada media gambar yaitu permainan puzzle yang berupa jigsaw puzzle. Permainan puzzle merupakan permainan gambar yang berupa media visual karena hanya dicerna melalui indera penglihatan saja. Menurut Srimulyanti (2016) bahwa puzzle merupakan media dimainkan dengan membongkar dan menyatukan bagian-bagian untuk membentuk gambar atau tulisan. Di antara penggunaan jenis-jenis media pembelajaran, puzzle merupakan permainan paling umum digunakan dalam media pembelajaran sederhana dapat dimanfaatkan dalam sekolah. Puzzle merupakan pemainan yang meningkatkan kemahiran otak anak untuk menyusun dan menata perbagian sehingga membentuk sebuah gambar. Menurut School Pouring Rights (2017) puzzle pertama kali dibuat oleh John Spilsbruy tahun 1776 dengan tujuan membantu pembelajaran geografi pada masa itu tentang lokasi antar negara.

Permainan puzzle adalah permainan yang menantang daya kreativitas dan ingatan lebih mendalam karena muncul motivasi untuk senantiasa mencoba untuk memecahkan masalah, namun menyenangkan dan bisa berulang-ulang. Permainan ini akan memberikan efek ketagihan untuk mencoba sehingga dapat berhasil menyelesaikan (Andang, 2013). Tujuan penggunaan game puzzle memudahkan bagi anak-anak untuk memahami dan mempelajari sejarah sehingga melalui game puzzle tersebut siswa dapat belajar menggunakan media permainan dalam game puzzle. 
Penggunaan puzzle layak untuk dilakukan, dengan pertimbangan bahwa adanya pemanfaatan teknologi akan memudahkan bagi siswa untuk melakukan pembelajaran, kebosanan siswa akan dihindarkan. Media ini memberikan fasilitas bermain dan sekaligus untuk media belajar, sehingga penggunaan puzzle menjadikan proses belajar menyenangkan. Jadi disimpulkan bahwa puzzle merupakan alat permainan yang kreatif sehingga dapat mendukung kemampuan dalam berfikir anak. Menurut Maysky Mary (dalam Resiyati, 2010:20) sisi edukasi mainan jenis puzzle berfungsi untuk: (1) Melatih konsentrasi, ketelitian dan kesabaran, (2) Memperkuat daya ingat, (3) Mengenalkan pada sistem dan konsep hubungan, (4) Memilih gambar/bentuk, dapat melatih berfikir matematis (otak kiri).

Peneliti datang ke sekolah untuk menemui kepala sekolah, guru dan siswa untuk mewawancarai guru dan siswa. Setelah mewawancarai dengan guru dan siswa di sekolah MI ARRaudhah Lawang dapat ditarik kesimpulan permasalahan yang terjadi adalah : (1) Siswa sulit untuk berkonsentrasi pada pembelajaran, (2) Siswa sulit memahami materi, (3) Materi bacaan yang terlalu banyak, dan (4) Kurangnya minat membaca. Permasalahan yang terjadi dalam pembelajaran materi sejarah menjadikan siswa mengalami keterbatasan dalam penerimaan materi yang diberikan kepada oleh guru. Dari permasalahan tersebut disimpulkan bahwa dibutuhkan media yang sesuai agar kegiatan belajar mengajar dapat berjalan dengan baik.

Bahwa tujuan dari pengembangan media pembelajaran adalah untuk menghasilkan multimedia berfitur puzzle kemerdekaan Indonesia yang valid pada materi sejarah pembahasan perjuangan memproklamasikan kemerdekaan Indonesia kelas 5 di MI AR-Raudhah Lawang. Penggunaan puzzle layak untuk dilakukan, dengan pertimbangan bahwa adanya pemanfaatan teknologi akan memudahkan bagi siswa dalam proses pembelajaran, kebosanan siswa dapat dihindarkan.

\section{METODE}

Model penelitian menggunakan model Sadiman yaitu meliputi: (1) Identifikasi kebutuhan, (2) Perumusan Tujuan, (3) Perumusan butir-butir materi, (4) Perumusan alat pengukur keberhasilan, (5) Penulisan naskah media, (6) Produksi, (7) Uji coba, (8) Revisi, dan (9) Media siap digunakan dalam pembelajaran. Akan tetapi Menurut Indarwati (2015) model pengembangan Sadiman dikhususkan untuk audio, slide, dan video sehingga untuk pengembangan multimedia kurang cocok pada langkah 5 dan 6 . Maka kedua langkah tersebut diganti dengan model pengembangan William W.Lee dan Diana L. Owens, yaitu langkah desain dan pengembangan. Penggunaan model Penelitian dan Pengembangan diatas, dapat digambarkan pada bagan di bawah ini:

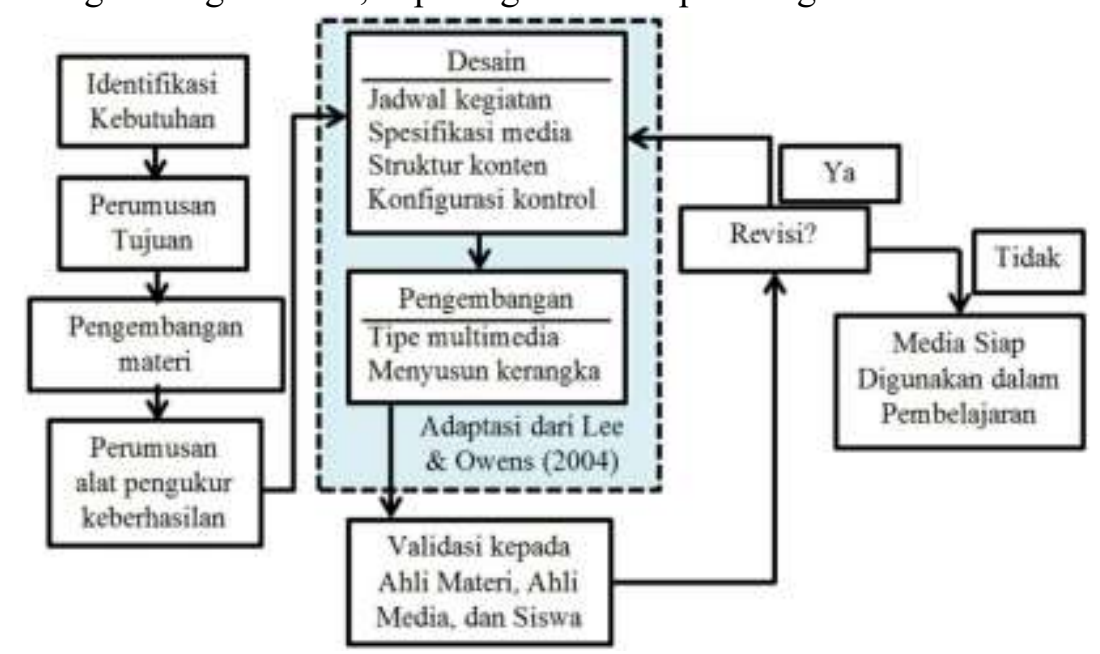

Gambar 1. Prosedur Pengembangan Adaptasi dari Model Pengembangan Arif S. Sadiman dan Lee \& Owens (Desain dan Pengembangan) (Sadiman, 2012:101) 
Multimedia kemerdekaan Indonesia divalidasi dilakukan oleh ahli media yaitu bapak Henry Praherdhiono dan ahli materi adalah ibu Maryam. Pada audiens adalah siswa kelas 5 MI ARRaudhah Lawang yang dilakukan menjadi tiga tahap yaitu : (1) Uji coba perseorangan yang berjumlah 2 siswa, (2) Uji coba kelompok kecil yang berjumlah 7 siswa, dan (3) uji coba lapangan berjumlah 22 siswa. Penelitian pengembangan ini menggunakan beberapa instrumen untuk mengumpulkan data, yaitu: Instrumen bentuk angket untuk ahli materi, ahli media, dan siswa, tes hasil belajar untuk siswa.

Teknik analisis data dan evaluasi para ahli pada penelitian pengembangan multimedia berbasis komputer pembelajaran perjuangan memproklamasikan kemerdekaan Indonesia menggunakan data kualitatif dan kuantitatif berupa persentase. Data kuantitatif berupa angket kuesioner, data skoring, dan format evaluasi yang diperoleh dari ahli media dan ahli materi digunakan untuk mengukur persentase dari hasil pengumpulan data pada saat penelitian awal. Data kualitatif diperoleh dari ahli media dan ahli materi berupa hasil saran dan tanggapan yang diberikan berguna sebagai bahan untuk revisi produk pengembangan multimedia berbasis komputer.

\section{Kriteria interpretasi multimedia pembelajaran}

Pedoman yang digunakan dalam menilai kelayakan multimedia berbasis komputer pembelajaran perjuangan memproklamasikan kemerdekaan Indonesia menggunakan kriteria valid, cukup valid, kurang valid, dan tidak valid, yang menggunakan adaptasi kriteria tingkat kelayakan dari Arikunto (2010). (1) Apabila hasil analisis memperoleh kriteria A (76-100) maka media tersebut termasuk kualifikasi valid dan layak digunakan untuk pembelajaran di dalam kelas. (2) Apabila hasil analisis memperoleh kriteria B (51-75) maka media tersebut termasuk kualifikasi cukup valid dan layak digunakan untuk pembelajaran di dalam kelas. (3) Apabila hasil analisis memperoleh kriteria C (26-50) maka media tersebut termasuk kualifikasi kurang valid dan harus direvisi yang artinya multimedia berbasis komputer pembelajaran perjuangan memproklamasikan kemerdekaan Indonesia tidak layak digunakan untuk pembelajaran di dalam kelas. (4) Apabila hasil analisis memperoleh kriteria D $(<25)$ maka media tersebut termasuk kualifikasi tidak valid dan harus diganti.

\section{Kriteria interpretasi data hasil belajar}

Dalam pembelajaran multimedia kemerdekaan Indonesia ini dapat dikatakan berhasil ketika skor diperoleh siswa dari tes hasil belajar melebihi KKM (Kriteria Ketuntasan Minimum). KKM untuk pembelajaran IPS adalah $\geq 70$. Pada data tes hasil belajar dari seluruh siswa kelas 5 memenuhi KKM harus lebih dari $80 \%$ agar multimedia interaktif dapat digunakan untuk guru maupun untuk siswa dalam pembelajaran individual.

Mengolah data hasil pre-test dan post-test dilakukan untuk membandingkan hasil belajar sebelum dan sesudah penggunaan media dalam pembelajaran. Perbandingan ini menggunakan acuan Kriteria Ketuntasan Minimal (KKM) mata pelajaran IPS di MI AR-Raudhah Lawang yaitu 70.

Menggunakan kriteria tingkat keberhasilan tes hasil belajar dari Arikunto (2010). (1) Apabila hasil analisis tes memperoleh kriteria A (80-100) maka media tersebut termasuk kualifikasi efektif dan layak digunakan untuk pembelajaran di dalam kelas. (2) Apabila hasil analisis memperoleh kriteria B (60-79) maka media tersebut termasuk kualifikasi cukup efektif dan layak digunakan untuk pembelajaran di dalam kelas. (3) Apabila hasil analisis memperoleh kriteria C (40-59) maka media tersebut termasuk kualifikasi kurang efektif dan harus direvisi yang artinya multimedia berbasis komputer pembelajaran perjuangan memproklamasikan kemerdekaan Indonesia tidak layak digunakan untuk pembelajaran di dalam kelas. (4) Apabila hasil analisis memperoleh kriteria $\mathrm{D}(<40)$ maka media tersebut termasuk kualifikasi tidak efektif dan harus diganti. 


\section{HASIL}

Berdasarkan hasil penelitian telah dilaksanakan uji coba kepada satu orang ahli media pembelajaran dan satu orang ahli materi guru Sekolah Dasar atau Madrasah Ibtidaiyah Kelas V. Sedangkan data audiens, peneliti mengambil sampel sebanyak dua siswa untuk uji coba perseorangan, tujuh siswa untuk uji coba kelompok kecil, dan 22 siswa untuk uji coba lapangan.

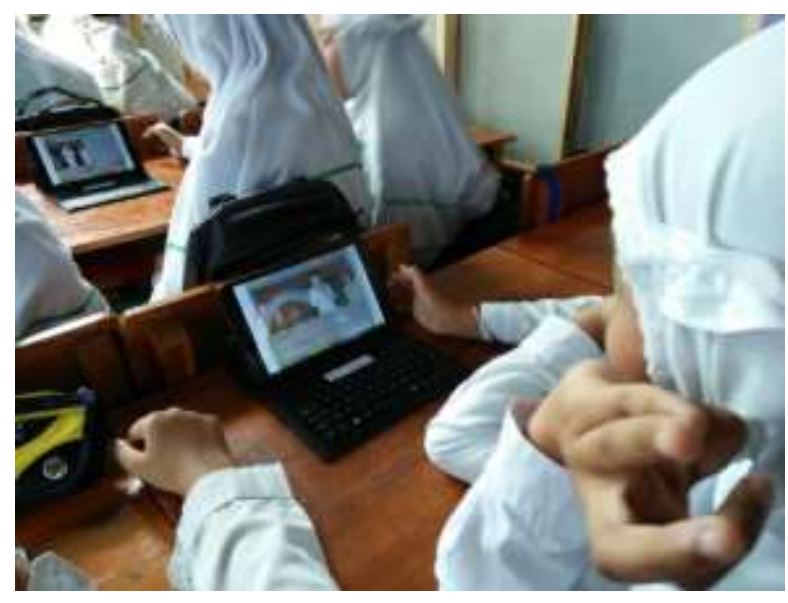

Gambar 2. Foto Uji Coba Multimedia pada Siswa Kelas Lima

Setelah melakukan analisis, hasil validasi multimedia ini dinyatakan valid dengan hasil perhitungan ahli media mendapatkan skor sebesar 97,85\%, ahli materi mendapatkan skor sebesar $89,81 \%$, dan audiens dari uji perorangan sebesar $95,19 \%$, uji coba kelompok kecil sebesar $92,41 \%$, dan uji coba lapangan sebesar $86,31 \%$.

Pada penjelasan sebelumnya, disimpulkan bahwa multimedia kemerdekaan Indonesia pelajaran tematik bahasan perjuangan memproklamasikan kemerdekaan Indonesia kelas $\mathrm{V}$ semester dua, terdapat valid pada setiap validasi yang dilakukan kepada ahli media, ahli materi, dan audiens yang terbagi uji coba perorangan, uji coba kelompok kecil, dan uji coba lapangan. Disimpulkan bahwa multimedia kemerdekaan Indonesia telah dinyatakan valid sebagai media pembelajaran.

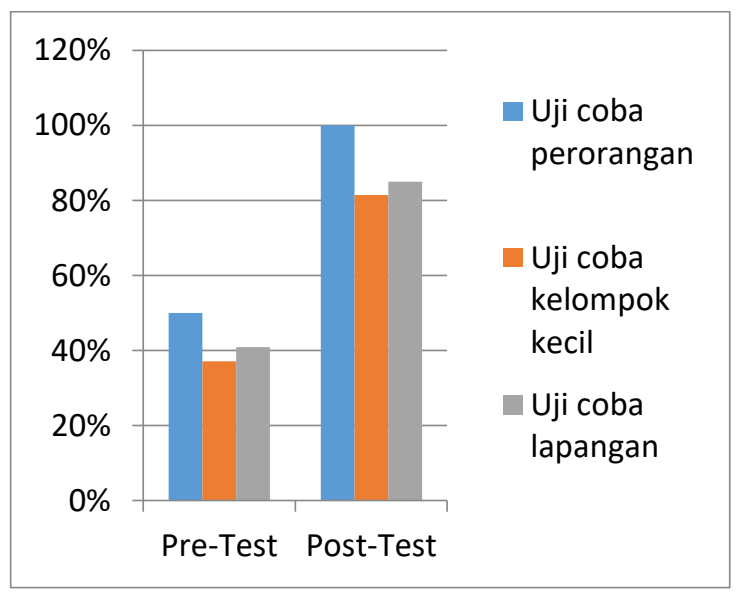

\section{Gambar 3. Grafik Hasil Pre-Test dan Post-Test Setiap Uji Coba Pemanfaatan Multimedia}

Keefektifan multimedia ini dibuktikan pada hasil belajar setelah menggunakan media hampir seluruh audiens (siswa) dapat memenuhi KKM $(\geq 70)$. Pada uji coba perseorangan yang dilakukan pada 2 orang siswa, skor rata-rata pre-test adalah $50 \%$ dan pada post-test adalah $100 \%$, terjadi peningkatan sebesar 50\%, dan persentase siswa yang memenuhi KKM dari $0 \%$ menjadi meningkat 
sebesar $100 \%$. Pada uji coba kelompok kecil yang dilakukan pada 7 orang siswa, skor rata-rata pre-test adalah $37,14 \%$ dan pada post-test adalah $81,43 \%$, terjadi peningkatan sebesar $44,28 \%$, dan persentase siswa yang memenuhi KKM dari $0 \%$ menjadi meningkat sebesar $85,71 \%$ dari 8 siswa 7 siswa memenuhi KKM dan hanya 1 siswa tidak memenuhi. Pada uji coba lapangan yang dilakukan pada 22 orang siswa, skor rata-rata pre-test adalah 40,9\% dan pada post-test adalah $85 \%$, terjadi peningkatan sebesar $44,09 \%$, dan persentase siswa yang memenuhi KKM dari $0 \%$ menjadi meningkat sebesar $81.8 \%$ dari 22 siswa 18 siswa memenuhi KKM dan 4 siswa yang tidak memenuhi KKM.

\section{PEMBAHASAN}

Pada hasil penelitian ini dinyatakan valid dan efektif untuk dimanfaatkan dalam kegiatan sekolah dasar dengan meningkatnya hasil belajar pada siswa kelas $\mathrm{v}$ sekolah dasar. Hasil ini sejalan dengan penelitian Wulandari (2017) yang menyatakan bahwa multimedia yang telah melalui tahap uji kelayakan produk dan kriteria kepraktisan, kemenarikan, dan keefektifan menyatakan layak dimanfaatkan dalam kegiatan pembelajaran kelas dan hasil belajar siswa setelah menggunakan multimedia mengalami peningkatan. Didukung oleh Dalal (2014:10) menyatakan pembelajaran yang memanfaatkan multimedia dapat meningkatkan hasil belajar.

Pada saat uji coba multimedia terlihat siswa sangat antusias dan senang saat menggunakan multimedia. Sejalan dengan Akbar (2016:1124) bahwa menggunakan multimedia dapat membuat siswa merasa senang dan termotivasi dalam kegiatan pembelajaran.

Penggunaan multimedia merupakan alternatif untuk memenuhi tujuan belajar yang mampu memperjelas dan menyampaikan informasi materi. Sejalan dengan media pendidikan merupakan sumber belajar yang dapat menyalurkan pesan sehingga membantu mengatasi hambatan-hambatan yang ada berupa hambatan kultural dan hambatan lingkungan (Sadiman, 2014).

Faktor penting dalam multimedia adalah materi yang digunakan, materi menyesuaikan karakteristik siswa kelas 5 yaitu suka bermain, suka gambar yang menarik perhatian, dan menyukai hal-hal yang baru. Penggunaan bahasa pada multimedia harus singkat, padat, dan jelas agar penyampaian pesan ke peserta didik dapat berhasil.

Petunjuk pemanfaatan untuk multimedia ini bisa membantu guru dan siswa dalam penggunaan. Petunjuk pemanfaatan multimedia dapat memudahkan dalam pengoperasian dan guru pun dapat membimbing siswa dalam penggunaannya. Sejalan dengan pendapat Kustiawan (2013:169) jika terdapat materi pada program yang sulit maka bantuan bimbingan dan arahan dari guru atau orang tua dibutuhkan.

Dengan adanya petunjuk pemanfaatan, navigasi juga perlu diperhatikan karena navigasi yang mudah dapat membantu guru dan siswa mudah memahami penggunaan multimedia. Pengaturan navigasi yang mudah dapat memudahkan siswa mempelajari konten yang terdapat di dalam multimedia dan belajar secara runtut (Akbar, 2016:1124).

Penyusunan media yang dapat memudahkan siswa mempelajari konten dan belajar secara sistematis. Multimedia ini dilengkapi beberapa komponen, yaitu (1) judul multimedia dengan materi memproklamasikan kemerdekaan Indonesia, (2) petunjuk penggunaan multimedia agar memudahkan siswa dalam menggunakan, (3) tampilan kompetensi yang berisi kompetensi dasar, indikator, dan tujuan pembelajaran yang akan dicapai dalam pemanfaatan multimedia, (4) menu pemilihan stage yang terdapat materi dan pemainan puzzle, (5) tampilan video dan animasi materi, (6) tampilan gambar disertai teks narasi dan percakapan antar tokoh tentang materi, (7) tampilan permainan puzzle dengan gambar yang berhubungan dengan materi, (8) tampilan setelah penyelesaian permainan disertai dengan rangkuman dari materi yang telah dipelajari.

Multimedia kemerdekaan Indonesia memiliki beberapa kelebihan yaitu: (1) multimedia dapat digunakan pada semua jenis komputer, (2) dapat digunakan secara individu maupun kelompok, (3) 
terdapat pemainan yang memotivasi dan menghilangkan rasa kejenuhan siswa, dan (4) terdapat jenis-jenis media berupa teks, gambar, animasi, audio, dan video dalam multimedia kemerdekaan Indonesia.

Multimedia kemerdekaan Indonesia memiliki beberapa kekurangan, yaitu (1) penggunaan multimedia ini harus menggunakan teknologi berupa komputer, tetapi beberapa sekolah memiliki keterbatasan dalam hal pengadaan komputer, dan (2) multimedia hanya sebatas materi memperjuangkan proklamasi kemerdekaan Indonesia, maka perlunya pengembangan lebih lanjut untuk menyempurnakan.

\section{SIMPULAN}

Berdasarkan hasil validasi pada ahli materi, ahli media, dan hasil uji coba multimedia kepada siswa dengan materi memperjuangkan kemerdekaan Indonesia menyatakan layak dan dapat dimanfaatkan dalam pembelajaran. Multimedia kemerdekaan Indonesia dinyatakan efektif dan menarik minat siswa dalam penggunaannya.

Produk multimedia yang dihasilkan dapat dimanfaatkan dengan maksimal dalam kegiatan pembelajaran, maka ada beberapa saran (1) untuk guru mata pelajaran yaitu membaca petunjuk pemanfaatan dengan cermat, menjelaskan secara singkat kepada siswa tentang perjuangan memproklamasikan kemerdekaan Indonesia sebelum memanfaatkan produk multimedia, dalam pemanfaatan multimedia guru membimbing siswa untuk memperoleh isi materi jika diperlukan untuk mengulangi materi pada multimedia, dan memfasilitasi tanya jawab tambahan untuk mengingat materi pada produk multimedia ini. (2) Saran untuk siswa harus mempunyai keterampilan dalam pengoperasian komputer untuk memudahkan dalam penggunaan multimedia kemerdekaan Indonesia.

\section{DAFTAR RUJUKAN}

Akbar, T. N. (2016). Pengembangan Multimedia Interaktif IPA Berorientasi Guided Inquiry pada Materi Sistem Pernapasan Manusia Kelas V SDN Kebonsari 3 Malang. Jurnal Pendidikan: Teori, Penelitian, dan Pengembangan, 1(6), 1120-1126. (Online), (http://journal.um.ac.id/index.php/jptpp/article/download/6456/2737), 18 Mei 2019.

Andang, Ismail. (2013). Edukatif Games. Yogyakarta: Pro-U Media.

Arikunto, S. (2010). Prosedur Penelitian: Suatu Pendekatan Praktik (Edisi Revisi Kedua). Jakarta: PT. Rineka Cipta.

Asrofi. (2016). Pengembangan Game Interaktif "Math Finder" Untuk Siswa Kelas 2 Pada Mata Pelajaran Matematika Pokok Bahasan Penjumlahan dan Pengurangan di SDN Karangbesuki 1 Malang (Skripsi) Universitas Negeri Malang, Malang, Indonesia.

Dalal, M. (2014). Impact of Multi-Media Tutorials in a Computer Science Laboratory Course--An Empirical Study. Electronic Journal of e-Learning, 12(4), 366-374. (Online), (http://files.eric.ed.gov/fulltext/EJ1035651 .pdf), diakses 18 Mei 2019.

Kapp, K. M. (2012). The gamification of learning and instruction: game-based methods and strategies for training and education. John Wiley \& Sons.

Kustiawan, U. (2018). Sumber dan Media Pembelajaran Anak Usia Dini. KARYA DOSEN Fakultas Ilmu Pendidikan UM. (Online), (http://karya-ilmiah.um.ac.id/index.php/karya-dosenfip/article/download/75658/4851), diakses 24 Mei 2019.

Munandar, Utami. (2012). Pengembangan Kreativitas Anak Berbakat. Jakarta: Rineka Cipta.

Praherdhiono, Henry. (2017). Teknologi pada media pembelajaran Retrived April 29, 2019, from UAE Interact website: https://teknologipendidikan.org/teknologi-pada-media-pembelajaran-2/.

Purnama, Bambang Eka. (2013). Konsep Dasar Multimedia, Yogyakarta: Graha Ilmu.

Reiners, Torsten., \& Wood, L. C. (2015). Gamification in education and business. Springer. Retrived Januari 22, 2016, from google books: 
https://books.google.co.id/books?id=m_eSBQAAQBAJ\&printsec=frontcover\&hl=id\#v=onepage\&q $\& \mathrm{f}=$ false/.

Resiyati. (2010). Upaya Meningkatkan kemampuan Membaca Peta Lingkungan Setempat dengan Media Puzzle Peta pada Siswa Kelas IV SD Negeri 02 Petarukan Pemalang, Laporan Penelitan Tindakan Kelas Universitas Sebelas Maret. Retrived from https://eprints.uns.ac.id/8627/.

Rusman, (2009). Manajemen Kurikulum. Jakarta : Rajawali Press.

Sadiman, Arief S. (2014). Media Pendidikan:Pengertian, Pengembangan, dan Pemanfaatannya. Jakarta: Rajawali Pers.

School Pouring Rights. (2017). puzzle, permainan sederhana namun memiliki banyak manfaat. Retrived April 29, 2019, from UAE Interact website: https://www.schoolpouringrights.com/unik/puzzlepermainan-sederhana-namun-memiliki-banyak-manfaat/.

Srimulyanti. (2016). Pengembangan puzzle edukatif sebagai media pengenalan angka untuk kelompok A di TK Purbonegaran, Gondongkusuman, Yogyakarta (Skripsi). Universitas Negeri Yogyakarta. Retrived from https://eprints.uny.ac.id/42561/.

Sukirman. (2017). Peningkatan atmosfer belajar siswa generasi digital native melalui pembelajaran berbasis game. Portal Publikasi Ilmiah UMS. Retrieved from https://publikasiilmiah.ums.ac.id/handle/11617/9601.

Tobias, S., Fletcher, J. D., \& Wind, A. P. (2014). Game-Based Learning. In J. M. Spector, M. D. Merrill, J. Elen, \& M. J. Bishop (Eds.), Handbook of Research on Educational Communications and Technology (pp. 485-503). New York, NY: Springer New York. Retrived from https://doi.org/10.1007/978-1-4614-3185-5_38.

Wulandari, R., Susilo, H., \& Kuswandi, D. (2017). Penggunaan Multimedia Interaktif Bermuatan Game Edukasi untuk Meningkatkan Aktivitas dan Hasil Belajar Siswa Sekolah Dasar. Jurnal Pendidikan: Teori, Penelitian, dan Pengembangan, 2(8), 1024-1029. (Online), (http://journal.um.ac.id/index.php/jptpp/article/download/9759/4611), diakses 18 Mei 2019. 